Article

\title{
Combating the Tribo-Corrosion of LDX2404 Lean Duplex Stainless Steel by Low Temperature Plasma Nitriding
}

\author{
Xiaoying Li *(D), Wenbo Dou, Linhai Tian ${ }^{+} \mathbb{D}$ and Hanshan Dong \\ School of Metallurgy and Materials, University of Birmingham, Birmingham B15 2TT, UK; \\ douwenbouk@gmail.com (W.D.); tianlinhai@tyut.edu.cn (L.T.); H.dong.20@bham.ac.uk (H.D.) \\ * Correspondence: x.li.1@bham.ac.uk; Tel.: +44-121-4147105 \\ † Linhai Tian currently works in Taiyuan University of Technology, Taiyuan 030024, China.
}

Received: 2 August 2018; Accepted: 16 October 2018; Published: 19 October 2018

check for updates

\begin{abstract}
A lean duplex stainless steel, LDX2404, was DC plasma nitrided under a range of treatment conditions. The microstructure characterisation evaluation of the treated samples revealed that a dense, super-hard surface layer can be produced by low-temperature $\left(<450^{\circ} \mathrm{C}\right)$ plasma treatments. The original austenite phase became S-phase and the ferrite phase was supersaturated with nitrogen and $\varepsilon-\mathrm{Fe}_{3} \mathrm{~N}$ nitride precipitated from it. When plasma nitriding was carried out at above $450{ }^{\circ} \mathrm{C}$, chromium nitrides precipitated in the surface nitrided layer. Compared to the untreated samples, the surface hardness of the lean duplex stainless steel (DSS) is increased up to four times. The dry wear resistance increased when increasing the treatment temperature. In contrast, the low-temperature treated samples showed the best performance in the electrochemical corrosion and corrosion-wear tests; the performance of the high temperature $\left(>450{ }^{\circ} \mathrm{C}\right)$ plasma nitrided samples was found to be significantly worse than that of the untreated material.
\end{abstract}

Keywords: lean duplex stainless steel; plasma nitriding; wear; corrosion wear

\section{Introduction}

Duplex stainless steels (DSSs) are the materials of choice for the offshore gas and oil, petrochemical and chemical industries. This is mainly due to their good combination of high strength, good weldability and excellent corrosion-resistance in chloric environments [1]. To increase the cost-effectiveness of DSSs, a cost-saving lean DSS with reduced expensive alloying components (nickel and molybdenum) and increased manganese and nitrogen has been developed and widely used.

However, lean DSS is characterised by low hardness and poor wear resistance. Its severe wear in sea water (i.e., corrosion-wear) is a major concern for some demanding applications, such as subsea flexible flowlines, umbilical tubing, subsea manifolds etc. Therefore, how to improve the surface hardness and corrosion-wear resistance of lean DSS is a timely task for surface engineering researchers from both a scientific and a technological point-of-view.

Plasma nitriding has been one of the effective methods to improve the surface hardness and wear performance of the stainless steels. However, when the treatments were carried out at conventional temperatures $\left(450\right.$ to $600{ }^{\circ} \mathrm{C}$ ), the corrosion resistance of stainless steels severely deteriorated. This was caused by the chromium nitrides precipitation, which depleted the chromium content in the matrix, preventing the formation of a dense and continuous oxide layer on the surface [2,3]. Recently, a new low-temperature plasma surface alloying technique has been developed to achieve combined improvements in hardness, wear resistance and fatigue properties for austenitic stainless steels without reducing their corrosion properties due to the formation of a so-called S-phase, a nitrogen/carbon 
supersaturated, FCC structured solid solution [4]. A large amount of research has been carried out into the S-phase surface engineering of stainless steel and Co-Cr alloys [5-10]. However, limited work has been conducted on the low-temperature plasma nitriding of duplex stainless steels, particularly the lean DSS [11-13]. The reported research mainly investigated the surface layer structure, hardness and corrosion resistance of duplex stainless steels after plasma nitriding. Fewer research on tribocorrosion resistance was conducted. Additionally, the claim of a single S-phase formed on the surface of the DSS steels was mainly based on the XRD patterns only. Hence, the current paper aims to study the response of lean duplex stainless steels to plasma nitriding and the tribocorrosion properties of the plasma nitrided layers, which is a topic of scientific and practical importance.

In this work, a lean duplex stainless steel LDX 2404 was plasma nitrided (PN) for $10 \mathrm{~h}$ at temperatures ranging from $390{ }^{\circ} \mathrm{C}$ to $480{ }^{\circ} \mathrm{C}$ in a gas mixture of $25 \% \mathrm{~N}_{2}+75 \% \mathrm{H}_{2}$. The microstructures of the surface nitrided layers were characterised and their surface hardness, corrosion resistance, dry wear resistance and corrosion-wear properties were evaluated.

\section{Experimental}

\subsection{Material and Treatments}

The lean duplex stainless steel LDX 2404 (UNS No.S82441), provided by Outokumpu Stainless Ltd. (Sheffield, UK) was used as the substrate material. The nominal chemical composition of the material is shown in Table 1 [14]. The samples were cut into square slabs of $20 \times 20 \times 10\left(\mathrm{~mm}^{3}\right)$ and ground from 120 to 1200 grit using silicon carbide grinding papers. After grinding, the samples were polished using diamond paste of grades $9 \mu \mathrm{m}, 6 \mu \mathrm{m}, 3 \mu \mathrm{m}$ and $1 \mu \mathrm{m}$. Finally, the polished samples were ultrasonically cleaned with soapy water and acetone and dried under hot air. The etchant used for revealing microstructure was a solution containing $50 \mathrm{~mL}$ of $\mathrm{HCl}$ (39\% conc.), $25 \mathrm{~mL}$ of $\mathrm{HNO}_{3}(69 \%$ conc.) and $25 \mathrm{~mL}$ of distilled water.

Table 1. Chemical composition of 2404 lean duplex stainless steel.

\begin{tabular}{ccccccccccc}
\hline \multirow{2}{*}{ Outokumpu Steel Name } & \multicolumn{3}{c}{ International Steel Grade } & \multicolumn{4}{c}{ Chemical Composition, wt \% Typical Values } \\
\cline { 2 - 10 } & UNS & EN & ISO & C & N & Cr & Ni & Mo & Others \\
\hline LDX 2404 & S82441 & 1.4662 & $4662-824-41-X$ & 0.02 & 0.27 & 24.00 & 3.60 & 1.60 & $3 \mathrm{MnCu}$ \\
\hline
\end{tabular}

Plasma nitriding treatments were carried out in a $60 \mathrm{~kW}$ Klöckner DC plasma nitriding unit. The working table voltage and current were varied between 400 to $650 \mathrm{~V}$ and 1 to $10 \mathrm{~A}$ respectively in order to keep a constant temperature during the plasma treatment processes. A K-type thermocouple wire encased in an alumina ceramic sheath was used to measure the treatment temperature, which was inserted in a dummy sample aside of the samples. No pre-etching treatments were carried out on the samples. A mixed gas of $75 \% \mathrm{H}_{2}+25 \% \mathrm{~N}_{2}$ with a pressure of $4 \mathrm{mbar}(400 \mathrm{~Pa}$ ) was used for all the plasma treatments. At the beginning of the treatment process, the furnace vacuum was pumped down to $10^{-1} \mathrm{~Pa}$ before the gas mixture of hydrogen and nitrogen was introduced into the chamber. The heating process was controlled via increasing the voltage, current and gas pressure step by step until the set treatment temperature and pressure were achieved. The samples were then treated under the constant temperature and pressure for $10 \mathrm{~h}$. The samples were then cooled down to room temperature within the furnace in the vacuum when the treatment finished. A set of treatment temperatures, $390{ }^{\circ} \mathrm{C}$, $420{ }^{\circ} \mathrm{C}, 450{ }^{\circ} \mathrm{C}$ and $480{ }^{\circ} \mathrm{C}$, were chosen for the research and the detailed treatment conditions and the sample codes are listed in Table 2. 
Table 2. Sample codes and corresponding surface treatment conditions.

\begin{tabular}{cccc}
\hline Sample Code & Temperature, $^{\circ} \mathbf{C}$ & Time, $\mathbf{h}$ & Gas Composition \\
\hline PN390/10 & 390 & & \\
PN420/10 & 420 & 10 & $25 \% \mathrm{~N}_{2}+75 \% \mathrm{H}_{2}$ \\
PN450/10 & 450 & & \\
PN480/10 & 480 & & \\
\hline
\end{tabular}

\subsection{Microstructure Characterisation}

Microstructural characteristics of the plasma nitrided samples and the surface morphology of the wear and corrosion tested surfaces were observed by Jeol-7000 SEM, equipped with the EDX prober. A Philips X'Pert diffractometer with $\mathrm{Cu}-\mathrm{K} \alpha$ radiation was used to scan the XRD patterns of the nitrided layer and the software of X-Pert Highscore was used for identifying the phase constituents from the patterns. TEM microstructure analysis was carried out on one selected sample for the identification of the phases formed during the plasma nitriding, which could not be conclusively specified in XRD characterisation. The transmission electron microscope (TEM) sample was prepared in cross-sectional view by FIB/SEM (FEI Quanta 3D) and the surface layer structure formed during the plasma nitriding in the original austenite and ferrite grains was observed by JEOL2100 TEM equipment (JEOL Ltd., Akishima, Japan).

The depth profiles of the chemical composition of the nitrided samples was analysed by the LECO GDS-750 QDP Glow Discharge Optical Emission Spectrometer (GDOES). In addition to GDOES, the Oxford EDX detector adapted to the SEM instruments was used to identify the spot composition of the surface and cross-sections of plasma treated samples and INCA software was used to analyse the chemical elements.

\subsection{Mechanical and Chemical Properties}

The hardness of treated and un-treated samples was measured using the Mitutoyo MVK-H1 hardness tester with a Vickers indenter under the load of $0.05 \mathrm{kgf}$. A micro-hardness value reported is the average of five indents.

The corrosion resistance of the plasma nitrided DSSs was evaluated to compare with the un-treated samples by electrochemical corrosion tests in $3.5 \% \mathrm{NaCl}$ solution on an area of $1 \mathrm{~cm}^{2}$, using the Gamry Interface 1000 potentiostat with a reference electrode of $\mathrm{Ag} / \mathrm{AgCl}$. The open circuit potential (OCP) was first measured for $2 \mathrm{~min}$ (if a stable value was not obtained, a longer processing time used), and then potentiodynamic polarisation tests were carried out by sweeping from $-200 \mathrm{mV}$ of the OCP to $1200 \mathrm{mV}$ at a scan rate of $1 \mathrm{mV} / \mathrm{s}$ and three repeated tests were done for each sample. Built-in software (Echem Analyst, Gamry Instruments, Warminster, PA, USA) was used for data analysing.

Wear tests were carried out at room temperature for all samples using a reciprocating tribometer in air for dry wear and in simulated sea water $(3.5 \mathrm{wt} \% \mathrm{NaCl}$, the sample was preliminarily left in static contact with the solution for $0.5 \mathrm{~h}$ ) for corrosion-wear. The counterpart used was a WC-Cobalt ball $(\Phi=8 \mathrm{~mm})$, which reciprocated at a frequency of $1.12 \mathrm{~Hz}$ with a displacement amplitude of $4 \mathrm{~mm}$ for a sliding distance of $65 \mathrm{~m}$. Two normal loads of $30 \mathrm{~N}$ and $70 \mathrm{~N}$ were chosen for the dry wear tests. For the corrosion-wear tests only $70 \mathrm{~N}$ load was used as the $30 \mathrm{~N}$ load trials did not show any measurable wear for some of the plasma nitrided samples. The wear volume loss was calculated by measuring the cross-section of a wear track using a stylus profilometer and then multiplying by the length of the wear track. Three measurements were performed for each wear track and the average value is reported. 


\section{Results}

\subsection{Layer Structure and Chemical Composition of Plasma Nitrided Samples}

Figure 1 shows the SEM images of the longitudinal cross sections of LDX 2404 specimens, plasma nitrided at different temperatures for $10 \mathrm{~h}$. It can be clearly seen that a nitrided layer formed on the surface of all the nitrided specimens; the layer thickness increased with plasma treatment temperatures: from 5 and $6 \mu \mathrm{m}$ for the $390{ }^{\circ} \mathrm{C}$ treated PN390 and the $420^{\circ} \mathrm{C}$ treated PN420 samples to 17 and $26 \mu \mathrm{m}$ for $450{ }^{\circ} \mathrm{C}$ treated PN450 and $480{ }^{\circ} \mathrm{C}$ treated PN480 samples, respectively (Figure 1 and Figure 7a). It is noted that the nitrided layer of sample PN390 showed no cracks and better corrosion resistance to the etchant used than the substrate (Figure 1a). On the other hand, the high temperature $\left(450\right.$ and $\left.480{ }^{\circ} \mathrm{C}\right)$ treatments resulted in a surface layer with cracks and dark etched patches (Figure 1c,d). It has been confirmed by EDX analysis that the grains which showed good corrosion resistance are the original austenite grains, where a high content of nickel was probed.

Typical GDOES depth profiles of PN450 sample and the nitrogen content depth profiles for all the nitrided LDX 2404 samples are shown in Figure 2. It can be seen from Figure 2a that the nitrogen content at the surface reached a maximum value of $4.5 \mathrm{wt} \%$, and then decreased slowly to a value of approximately $3.5 \mathrm{wt} \%$ followed by a sharp drop to the substrate content. A small peak of carbon was also observed at the interface between the substrate and the surface layer, which may indicate that the nitrogen introduced during the treatment pushed the pre-existing carbon inwards. The thickness of the treated layer, based on the nitrogen-depth profile, is about $18 \mu \mathrm{m}$, which is consistent with the thickness observed by SEM (Figure 1c).
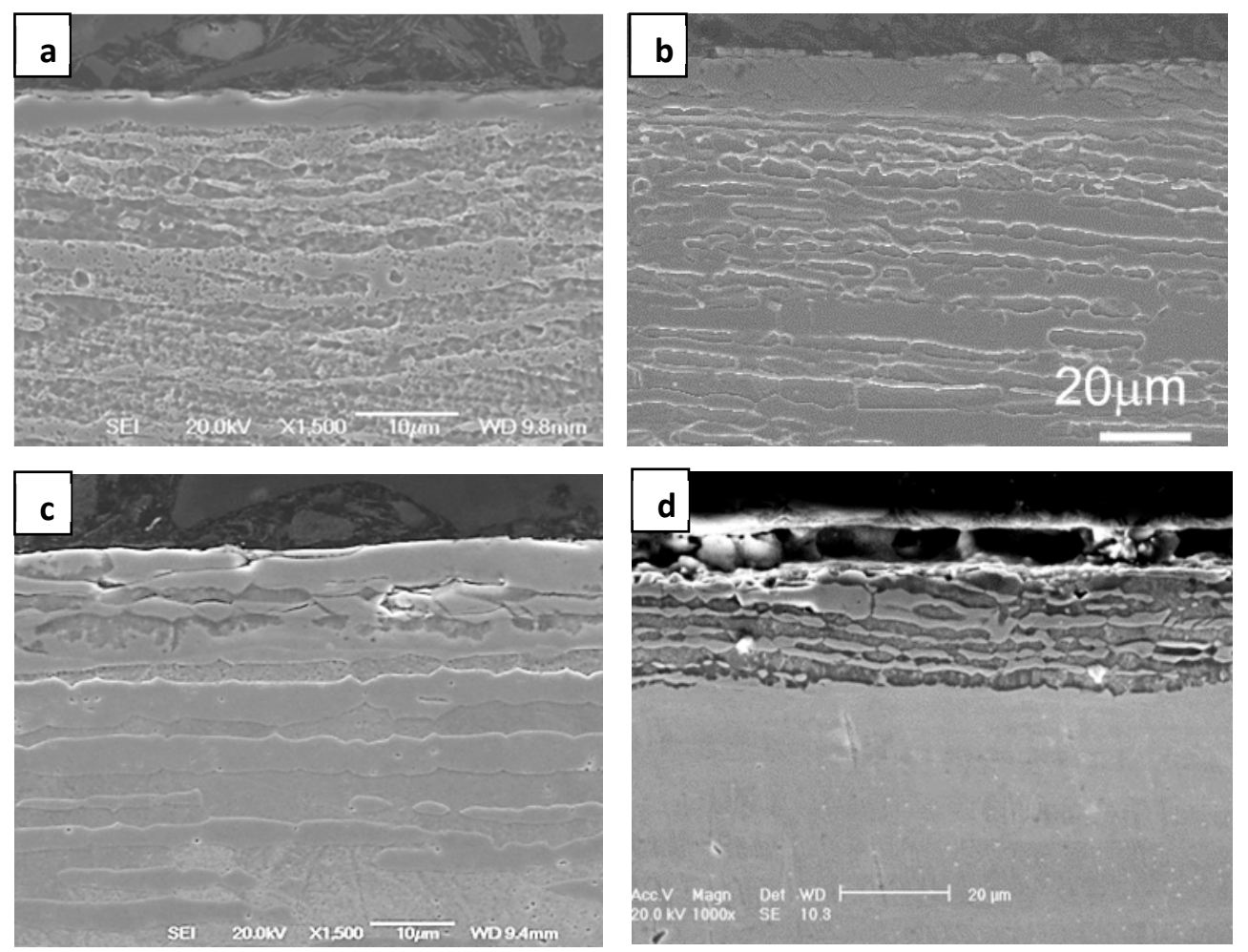

Figure 1. Longitudinal cross section SEM images of $10 \mathrm{~h}$ plasma nitrided LDX 2404 specimens at different temperatures: (a) 390, (b) 420, (c) 450 and (d) 480.

Figure $2 b$ shows the GDOES nitrogen-depth profiles of the samples after plasma nitriding for $10 \mathrm{~h}$ at different temperatures. It can be seen that the maximum nitrogen content introduced into the surface of the sample treated at $390{ }^{\circ} \mathrm{C}$ is approximately $0.9 \mathrm{wt} \%$, and the maximum nitrogen content for all the other samples, treated at $420^{\circ} \mathrm{C}, 450{ }^{\circ} \mathrm{C}$ and $480{ }^{\circ} \mathrm{C}$, is about $4.5 \mathrm{wt} \%$. A nitrogen plateau 
was observed for PN450 and PN480 samples, with an approximate nitrogen content of 3.5 wt \% and a carbon peak at the interface between the surface layer and the substrate was observed for PN420 and PN480 samples as well. This nitrogen content is much higher than the maximum equilibrium content of nitrogen in austenite, $2.7 \mathrm{wt} \%$, and in ferrite, $0.06 \mathrm{wt} \%$ [15], which shows alloying elements supersaturation characteristic of the S-phase.

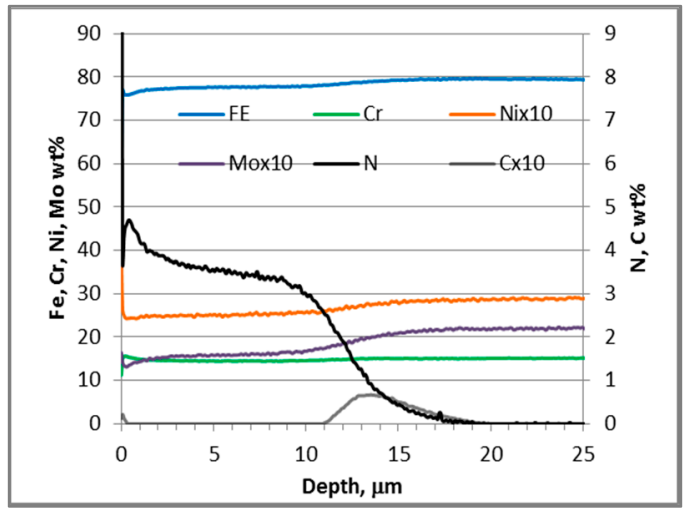

(a)

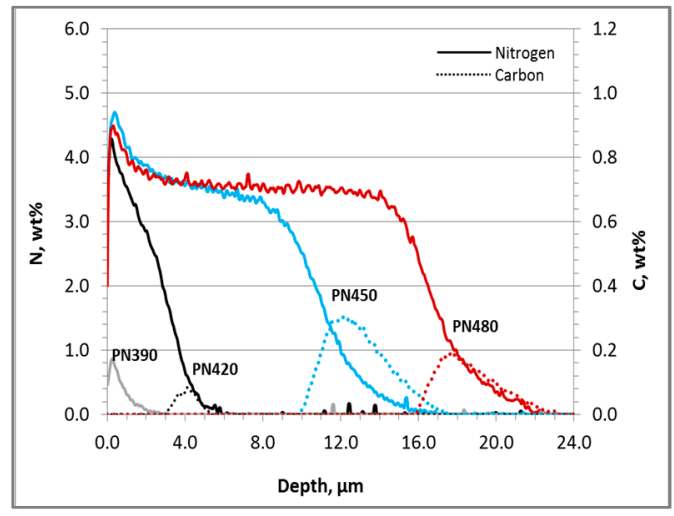

(b)

Figure 2. GDOES depth profiles of nitrided LDX 2404 samples, (a) elements distribution after $450{ }^{\circ} \mathrm{C}$ treatment; (b) comparison of nitrogen and carbon distributions for all the treated samples.

\subsection{Phase Identification of Plasma Nitrided Layers}

As shown in Figure 1, all the samples formed a surface layer during plasma nitriding treatment. The phase composition of the surface layers formed during the plasma treatments is presented in Figure 3, together with the XRD patterns from the as-received material for comparison. It can be seen that the pattern obtained from the as-received LDX2404 specimen shows a typical duplex structure of ferrite $(\alpha)$ and austenite $(\gamma)$ phases. Compared with the peaks of the as-received sample, all the treated specimens showed changes in the XRD patterns. For samples, treated below $480{ }^{\circ} \mathrm{C}$, the XRD patterns showed similar broadened peaks at $2 \theta=37.7,41.2,44.0$ and $48.0^{\circ}$, which could not be assuredly indexed to any of the nitride phases inserted as vertical lines in Figure 3: $\varepsilon-\mathrm{Fe}_{3} \mathrm{~N}, \gamma^{\prime}-\mathrm{Fe}_{4} \mathrm{~N}$ and $\mathrm{CrN}$. However, $\mathrm{CrN}$ precipitation in the surface layer of PN450 can be surely confirmed by the evidence of the poor corrosion resistance observed in Figures 5 and $6 \mathrm{~d}$. Only the peak at two theta of $44.0^{\circ}$ could be assigned to nitrogen expanded $\alpha_{\mathrm{N}}$ phase and very weak peaks at two theta of 41.2 and $48.0^{\circ}$ can be assigned to the S-phase. The XRD pattern taken from sample PN480 showed different features. The $(110) \alpha_{N}$ peak presents in the PN390, PN420 and PN450 samples disappeared and a few peaks of CrN, $\mathrm{Fe}_{3} \mathrm{~N}, \alpha$ and $\gamma$ can be indexed (Figure 3). The (200) peak of the S-phase presents for the relatively low temperature treated samples was detected with high intensity.

In order to identify the phases and microstructure of the low temperature plasma nitrided surface layers, TEM characterisation on the cross-sectional view of the PN420 sample was carried out. Figure $4 \mathrm{a}, \mathrm{b}$ show the microstructures and the corresponding selected area diffraction (SAD) patterns of the plasma nitrided surface layer from original austenite and ferrite grains, respectively. It can be found that a nitrogen supersaturated layer, or so-called S-phase layer, was formed from the original austenite grains as evidenced by the SAD pattern of an FCC structure, B $=[100]_{\text {fcc }}$ (Figure $4 \mathrm{a}$ ) from it. The calculated d-spacing of this S-phase is larger $(a=0.369 \mathrm{~nm})$ than that of the original austenite $(a=0.360 \mathrm{~nm})$, indicating nitrogen supersaturation in the interstitial sites of austenite. TEM observation on the surface layer formed from the original ferrite grains revealed that they consisted of nitrogen saturated ferrite $\left(\alpha_{\mathrm{N}}\right)$ and $\varepsilon-\mathrm{Fe}_{3} \mathrm{~N}$ needles as indexed in Figure $4 \mathrm{~b}$. No chromium nitride precipitate was observed in the surface layer of this PN 420 plasma nitrided LDX2404 sample. 


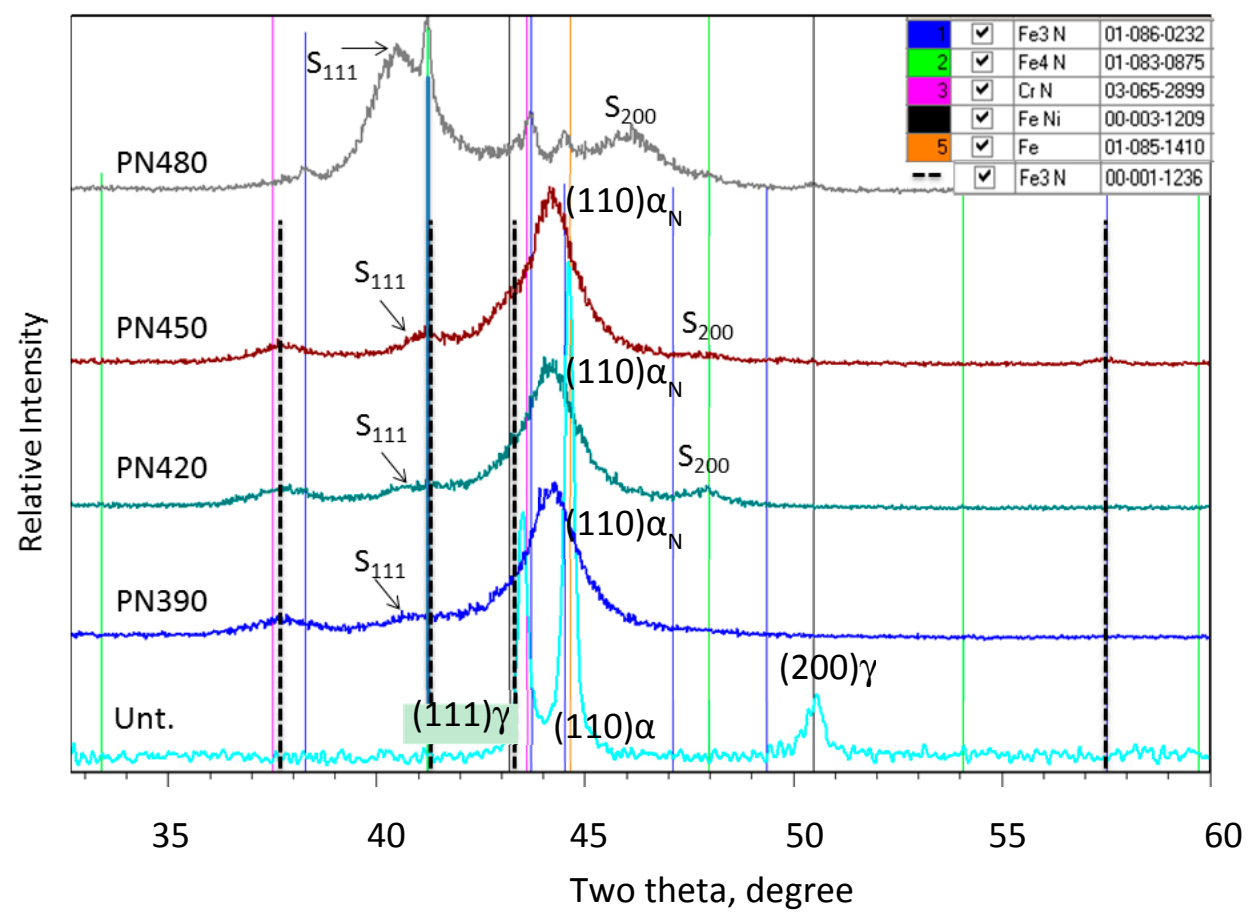

Figure 3. XRD patterns of plasma nitrided LDX2404 samples with as-received sample (Unt) for comparison.

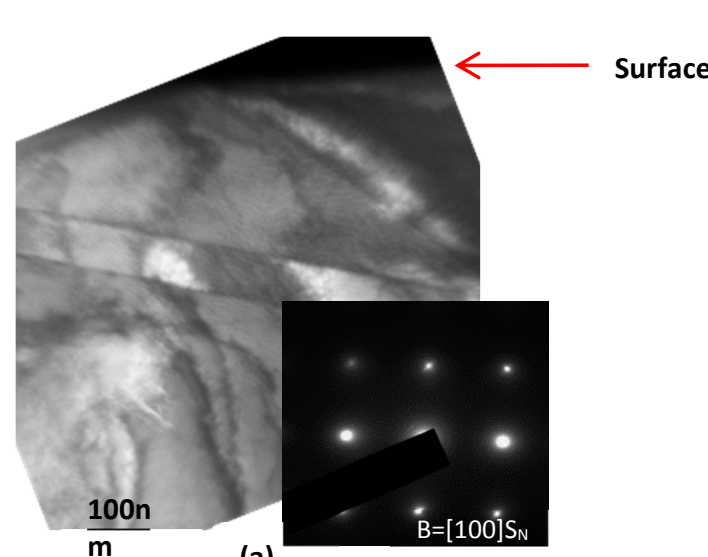

(a)

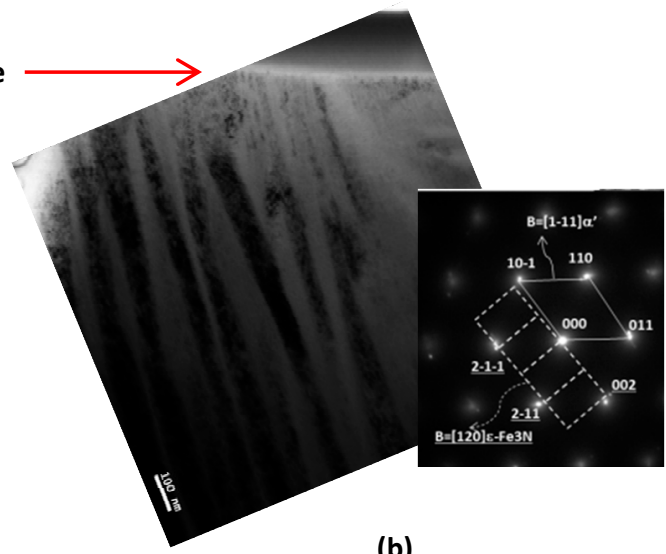

(b)

Figure 4. TEM microstructures and corresponding SAD patterns of PN420 sample, (a) nitrided surface layer from an original austenite grain; (b) nitrided surface layer from an original ferrite grain.

\subsection{Corrosion Resistance of Plasma Nitrided Samples}

The anodic polarisation curves of untreated and plasma nitrided samples are shown in Figure 5. It can be seen that except for PN390, all plasma treated samples showed a lower corrosion potential than the untreated sample. The corrosion current densities of all plasma nitrided samples were higher than the untreated sample. However, the anodic polarisation curves of PN390 and PN420 samples showed a wide passive region after an initial activation. In contrast, little to no passivation was observed for PN450 and PN480 samples.

The surface morphology of the untreated and plasma nitrided samples after the corrosion tests is shown in Figure 6. The surface of the untreated sample exhibits severe corrosion pits and selective corrosion along elongated grain boundaries with ferrite grains being corroded (Figure 6a) [16]. SEM observations on the surfaces of PN390 sample revealed no notable change after the corrosion test, indicating an improvement in the corrosion resistance over the untreated material (Figure 6b). Some 
intergranular corrosion and selective corrosion on the surface of ferrite grains (Figure 6c) were observed on the PN420 samples. However, these corrosion sites are shallower than the ones observed on the untreated sample. Clearly, the corrosion resistance of PN420 is better than the untreated sample but worse than PN390. The specimens treated at relatively high temperatures (PN450 and PN480) were severely corroded as evidenced in Figure 6b for a PN450 sample. It revealed that most of the tested area was corroded and those remaining patches of nitrided surface island are loosely attached. The degraded corrosion resistance of PN450 and PN480 samples indicates that chromium nitrides precipitated during the treatments, which depleted $\mathrm{Cr}$ (below $12 \mathrm{wt} \%$, proved by EDX analysis) in the adjacent areas of the chromium nitrides, deteriorating the corrosion resistance of the surface.

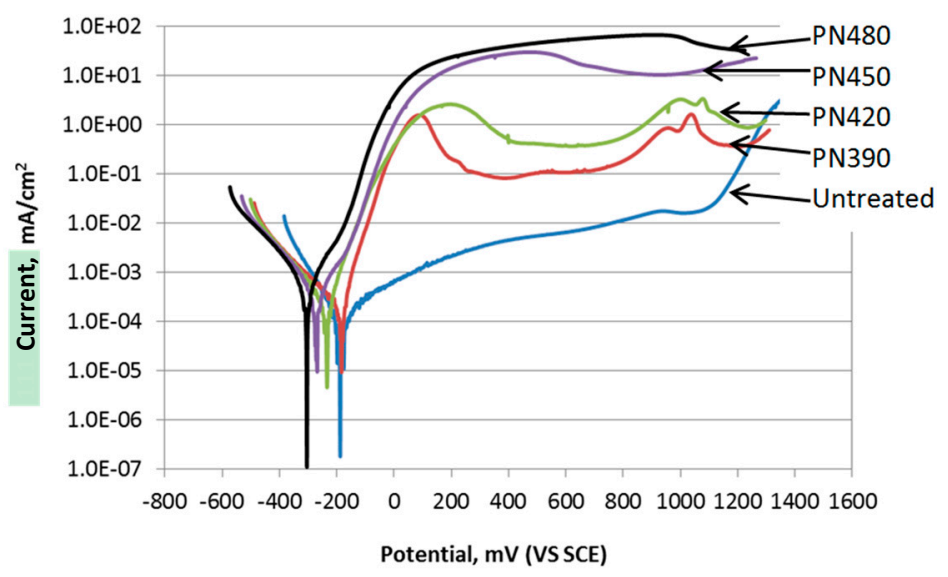

Figure 5. Anodic polarisation curves of untreated and plasma nitrided samples.

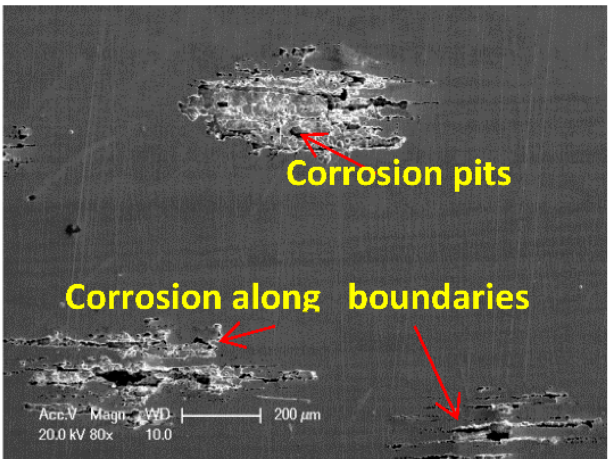

(a)

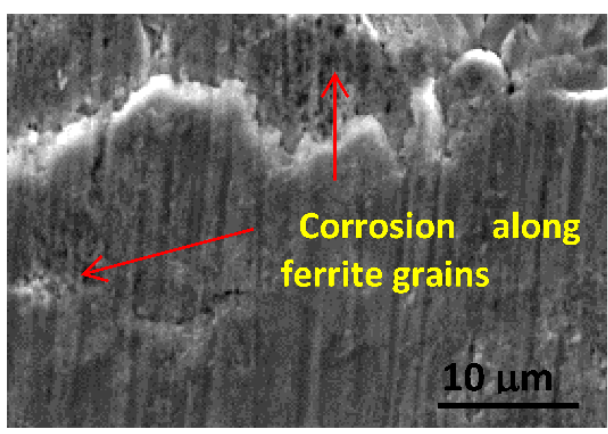

(c)

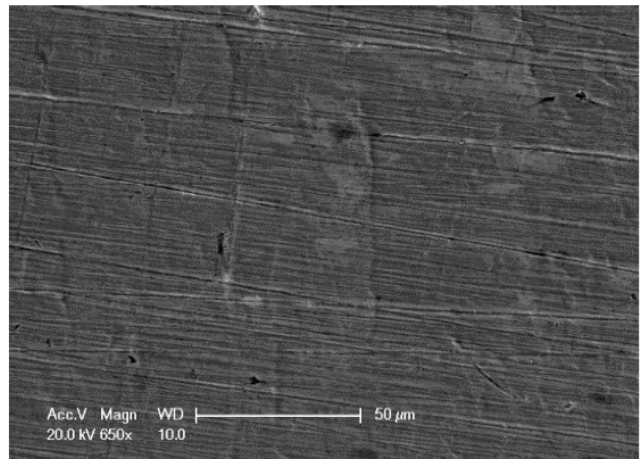

(b)

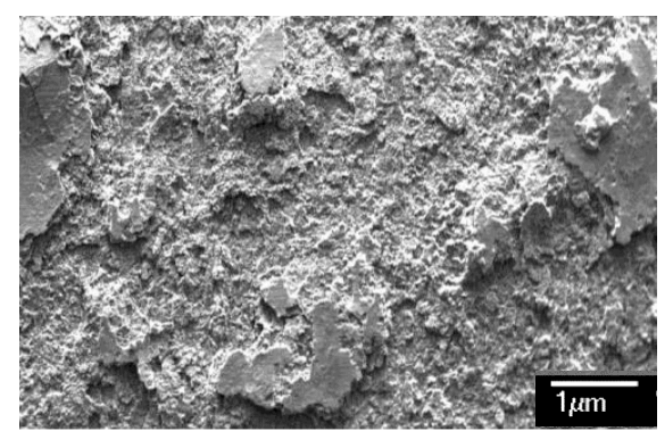

(d)

Figure 6. SEM images of post corrosion tested sample surfaces: (a) untreated; (b) 390PN; (c) PN420 and (d) PN450. 


\subsection{Surface Hardness, Dry Wear and Corrosion-Wear}

The thickness and the surface hardness of the plasma nitrided samples are shown in Figure 7a with the untreated one for comparison. It can be seen that all plasma nitrided samples showed an increase in surface layer thickness and hardness and the extent of the increment is treatment temperature dependent. The surface layer thickness is about 5-6 $\mu \mathrm{m}$ when plasma nitrided at 390 and $420{ }^{\circ} \mathrm{C}$. The surface layer thickness was increased significantly for the 450 and $480{ }^{\circ} \mathrm{C}$ treated samples, indicating a fast diffusion rate of nitrogen at high temperatures. The hardness of the PN450 and PN480 samples reached 1580 and $1680 \mathrm{HV}_{0.05}$ respectively, about four times the hardness of the untreated material (411 $\mathrm{HV}_{0.05}$ ), while for 390 and $420^{\circ} \mathrm{C}$ plasma nitrided samples, a moderate hardness increase was observed, which could be the effect of both the thin surface layer and the low content of nitrogen diffused in the surface layer.

Figure $7 \mathrm{~b}$ shows the results of wear tests conducted under a load of $30 \mathrm{~N}$ and $70 \mathrm{~N}$ for all the treated samples and the untreated samples. The wear volume loss measured under $30 \mathrm{~N}$ load was $3.14 \times 10^{7}, 5.20 \times 10^{6}$ and $2.80 \times 10^{5} \mu^{3}$ for the untreated, PN390 and PN420 samples, respectively. While for the PN450 and PN480 samples, the wear loss was below the detection limits. When the testing load increased to $70 \mathrm{~N}$, the measured wear loss was increased for all samples. It can be seen that the wear loss measured from PN390 sample $\left(7.56 \times 10^{7} \mu \mathrm{m}^{3}\right)$ is similar to the wear loss of the untreated sample $\left(8.32 \times 10^{7} \mu \mathrm{m}^{3}\right)$. This is mainly because the thin hardened case collapsed under the high load of $70 \mathrm{~N}$ and the debris from the damaged hardened surface acted as an abrasive third body, thus increasing the wear rate. The wear volume losses of PN420, PN450 and PN480 samples are $5.64 \times 10^{5}, 2.03 \times 10^{5}$ and $2.75 \times 10^{5} \mu \mathrm{m}^{3}$ respectively, which are much lower than that of the untreated material.

Conversely, the wear behaviour of the samples changed significantly when tested under the same load of $70 \mathrm{~N}$ but in corrosive simulated sea water (3.5 wt \% NaCl water) due to corrosion-wear. It can be seen from Figure $7 \mathrm{~b}$ that the corrosion-wear losses of the untreated and PN390 sample are $4.80 \times 10^{6}$ and $1.60 \times 10^{6} \mu \mathrm{m}^{3}$ respectively, which are less than the respective dry wear losses under the same load. The wear losses for the sample plasma nitrided at 420,450 and $480{ }^{\circ} \mathrm{C}$ were measured

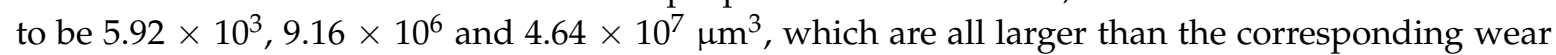
loss values measured under dry wear conditions. It is also noted that the corrosion wear resistance of PN450 and PN480 samples is even poorer than that of the untreated sample.

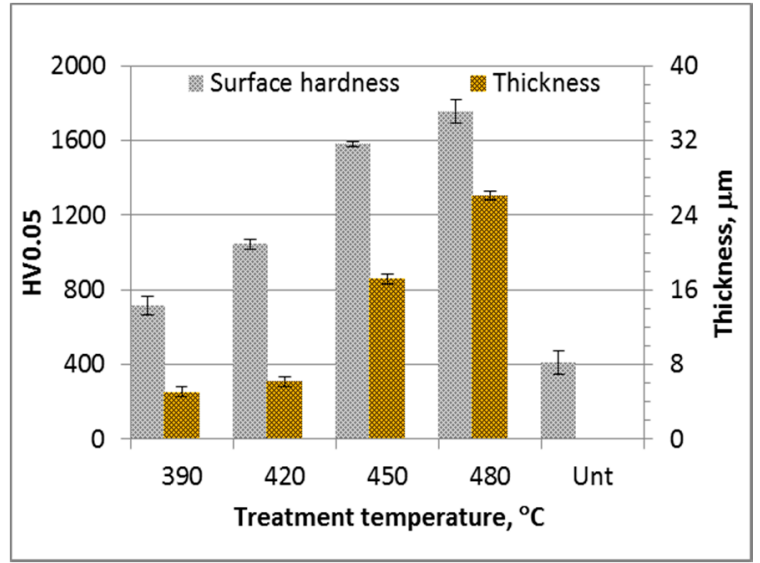

(a)

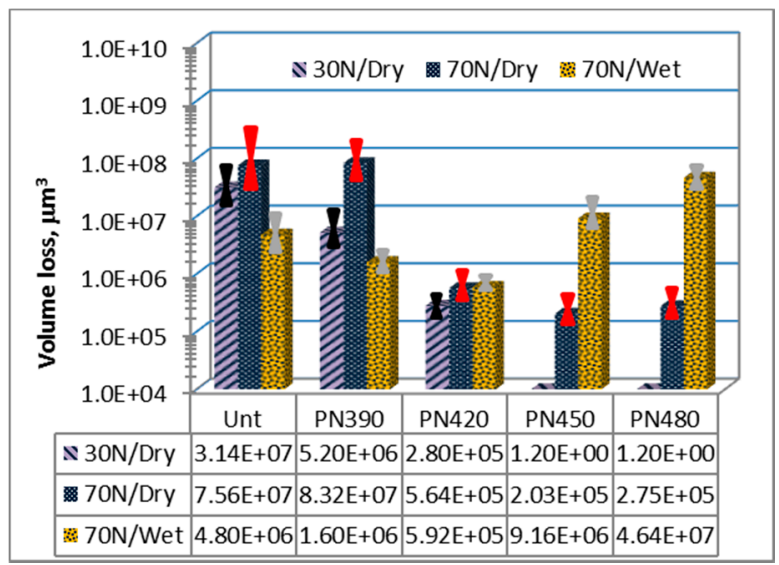

(b)

Figure 7. (a) Surface hardness and thickness of $10 \mathrm{~h}$-plasma nitrided and untreated samples; (b) Wear volume loss of untreated and plasma nitrided samples under $30 \mathrm{~N}$ and $70 \mathrm{~N}$ load with and without lubricant.

The SEM images of the wear tracks from some typical samples after dry wear and corrosion-wear tests under $70 \mathrm{~N}$ load are shown in Figure 8. The wear track produced on the untreated sample 
(Figure 8a) under dry wear conditions showed a width of approximately $1200 \mu \mathrm{m}$ with many severe wear grooves running parallel to the sliding direction, evidence of abrasive wear, and with some patches of galling and plastic deformation, evidence of adhesive wear. The dry wear tested surfaces of the PN420 and PN480 samples showed signs of mild wear, with only a few fine wear grooves visible over the original grinding marks, illustrating the good wear resistance of these samples (Figure 8c,e).

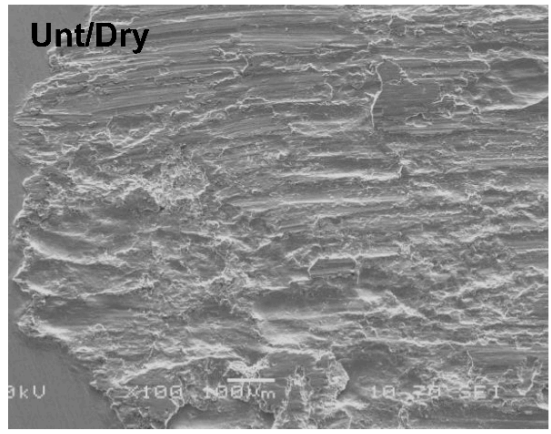

(a)

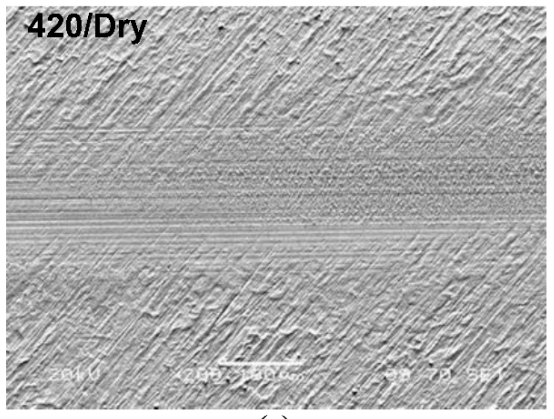

(c)

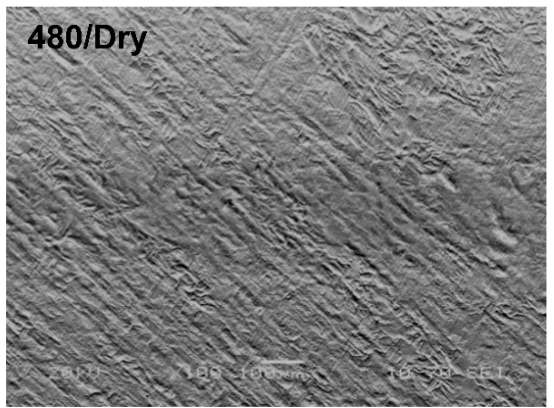

(e)

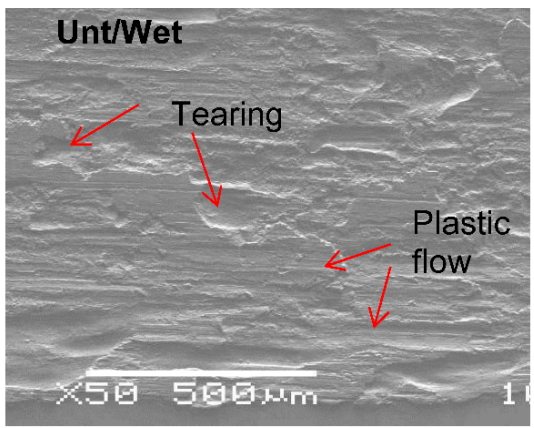

(b)

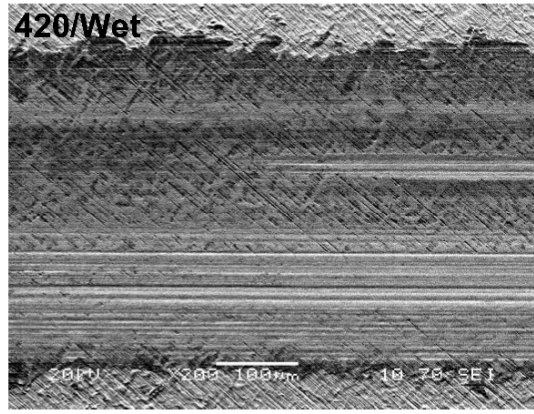

(d)

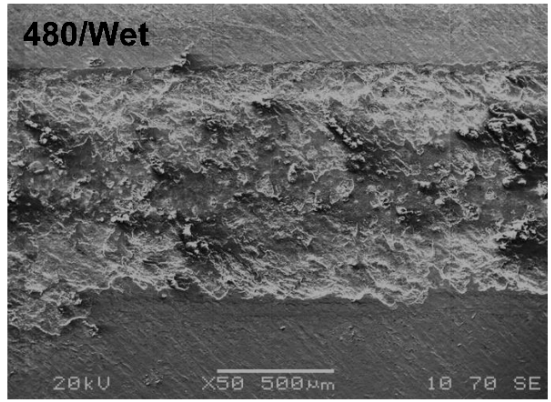

(f)

Figure 8. SEM images of the wear tracks tests under $70 \mathrm{~N}$ load with dry and wet (corrosion-wear) conditions, as indicated in the pictures: (a,b) untreated samples; (c,d) PN420 samples and (e,f) PN480 samples.

The corrosion-wear track formed on the untreated samples under $70 \mathrm{~N}$ load showed wear grooves with moderate galling as evidenced by the torn away materials patches and by plastic flow as denoted in Figure $8 \mathrm{~b}$, indicating limited lubrication effect during the wet wear test. Figure $8 \mathrm{~d}, \mathrm{f}$ is the post corrosion-wear test SEM images taken from the wear tracks formed on plasma nitrided PN420 and PN480 samples, respectively. The observation of the features of the tracks formed during corrosion wear supported the quantitative wear results shown in Figure 7b that PN420 sample outperformed PN450 sample in corrosion-wear. Only a few shallow wear grooves were formed during the wear test as the original grinding marks of the sample are still clearly visible in most of the worn surface area of PN420 sample. No corrosion pits or corrosion products can be seen on the surface and the wear tracks of the sample. 
A major contrast of the surface morphology of corrosion-wear tested PN450 and PN480 samples was observed. As an example, shown in Figure 8f, corrosion and wear occurred simultaneously during the test. Large pits and corrosion products are visible on the surface of the PN480 sample and accumulated on the wear track. The EDX analysis from this area showed a high content of oxygen together with chlorine and a much lower content of $\mathrm{Cr}$. This implicates that the precipitated $\mathrm{CrN}$ produced during the high temperature treatments reduced the corrosion resistance of the sample. The modified layer lost the protective function, exposing the substrate to the corrosive solution and mechanical wear.

\section{Discussion}

\subsection{The Response of LDX2404 Duplex Stainless Steel to Plasma Nitriding}

It is known that low temperature plasma (or gas) nitriding/carburising of austenitic stainless steels can produce a surface layer, which is a nitrogen/carbon supersaturated, FCC structured solid solution, so-called S-phase layer [4]. This S-phase not only increases the hardness and wear properties but also maintains a good corrosion resistance of austenitic stainless steels. This so-called S-phase surface engineering has been extended to the family of stainless steels, such as duplex, ferritic, martensitic and precipitation hardening stainless steels. Some researchers [17,18] claimed, based on XRD pattern analysis, that similar to austenitic stainless steels, single S-phase layer can be formed on the surfaces of duplex stainless steels by low temperature plasma/gas nitriding/carburising. It was speculated that as nitrogen is an austenite forming element, the ferrite in the original microstructure would first be converted to austenite and then form the S-phase. This assumption implied that not only the fcc structured austenite grains became S-phase, but also the bcc structured ferrite grains were transformed to fcc structured austenite with supersaturated nitrogen/carbon during low-temperature nitriding and/or carburising or formed S-phase.

TEM characterisation of the PN420 sample has clarified that the response of original austenite and ferrite in the DSSs to low temperature plasma nitriding is different. As evidenced in Figure 4, although the original austenite phase was transformed into the S-phase, the original ferrite phase was supersaturated with nitrogen and needle-like $\varepsilon-\mathrm{Fe}_{3} \mathrm{~N}$ nitrides were formed in it. This TEM observation has proved that a single S-phase layer cannot be formed on LDX2404 duplex stainless steels by low temperature plasma nitriding. This observation is consistent with our recent TEM observation [9] of the surface microstructure of a nitrided UNS S31803 duplex stainless steel.

\subsection{Corrosion-Wear}

Corrosion-wear is one of the most important properties required for some important applications. In this study the corrosion-wear behaviour of plasma nitrided lean duplex stainless steel, LDX2404 has been evaluated by conducting reciprocating sliding wear in $3.5 \% \mathrm{NaCl}$ solution.

It has been shown in Figure $7 \mathrm{~b}$ that the corrosion-wear for plasma nitrided LDX2404 decreased first and then increased with the plasma nitriding temperature with the minimum corrosion-wear being observed for PN420 treated samples. Clearly, this differs from the temperature dependence of dry wear of the plasma nitrided samples. In general, the dry wear of the plasma nitrided LDX2404 is reduced by increasing the treatment temperature (Figure $7 \mathrm{~b}$ ).

The difference in the treatment temperature dependence of dry wear and corrosion-wear could be attributed to the difference in their damage mechanisms. As discussed earlier, the loss of the plasma nitrided materials during dry wear is mainly via abrasive and adhesive wear. It is known that the abrasive wear of a surface is inversely proportional to its hardness and that adhesive wear of a surface is also affected by the plastic deformation and ductility of the surface. After plasma nitriding, the surface hardness has been effectively increased and the ductility and hence plastic deformation tendency could be reduced, which contributed to the reduced abrasive and adhesive wear during the dry reciprocating sliding wear. 
However, according to corrosion-wear theory $[19,20]$, the corrosion-wear of a surface depends not only on its hardness and hence wear resistance, but also on its corrosion resistance, i.e., depending on the synergy of wear and corrosion. The dry wear of low-temperature treated PN390 and PN420 samples is larger than the relatively high-temperature treated PN450 and PN480 samples (Figures 7b and 8c,e); however, the corrosion resistance of the low-temperature treated PN390 and PN420 samples is much better than the relatively high-temperature treated PN450 and PN480 samples (Figures 7b and 8d,f). Therefore, it is the synergy of the relatively good wear resistance and corrosion resistance that makes the best corrosion-wear behaviour of the PN420 treated samples.

Clearly, the optimum plasma treatment conditions for LDX2404 steel depend on the application conditions and hence the property requirement. For dry wear, PN450 is the best treatment, whilst for corrosion-wear in simulated sea water, PN420 is the optimal treatment condition.

\section{Conclusions}

Plasma nitriding of lean duplex stainless steel LDX 2404 has been conducted at temperatures ranging from 390 to $450{ }^{\circ} \mathrm{C}$ for $10 \mathrm{~h}$ in a gas mixture of $25 \% \mathrm{~N}_{2}$ and $75 \% \mathrm{H}_{2}$. Based on the experimental results obtained, the following conclusions can be drawn:

(1) Plasma nitriding of LDX 2404 lean duplex stainless steels forms a hardened surface layer with the thickness ranging from 5 to $28 \mu \mathrm{m}$ depending on the treatment temperatures. The surface hardness of the nitrided layers is between two and four times higher than that of the untreated sample.

(2) The response of the original duplex phases of ferrite and austenite to plasma nitriding differs greatly. When low temperature plasma nitrided $\left(T<450{ }^{\circ} \mathrm{C}\right)$, the original austenite grains in the surface of the LDX 2404 lean duplex stainless steel forms the S-phase (i.e., nitrogen supersaturated expanded austenite) whilst $\varepsilon-\mathrm{Fe}_{3} \mathrm{~N}$ needles were precipitated from nitrogen saturated ferrite grains $\left(\alpha_{\mathrm{N}}\right)$.

(3) The effect of plasma nitriding on the corrosion behaviour of LDX 2404 lean duplex stainless steel is closely related to the treatment temperature. The corrosion properties of the low-temperature treated PN390 and PN420 samples outperformed the relatively high-temperature treated PN450 and PN480 samples.

(4) When tested under $30 \mathrm{~N}$ and $70 \mathrm{~N}$, the dry wear resistance of LDX 2404 steel can be drastically improved by all the investigated plasma nitriding treatments, except for the PN390. The best performing PN450 sample can increase the dry wear resistance by $7.8 \times 10^{2}$ times than the untreated material.

(5) Unlike dry wear, the corrosion-wear resistance of LDX2404 material can be effectively improved only by low temperature PN390 and PN420 treatments since corrosion-wear is the synergy of wear and corrosion. The PN420 treatment can provide the best improvement in corrosion-wear resistance by 8.1 times than the untreated sample.

(6) Plasma nitriding for $10 \mathrm{~h}$ at $450{ }^{\circ} \mathrm{C}$ (i.e., PN450) and at $420^{\circ} \mathrm{C}$ (i.e., PN420) have been identified as the best plasma nitriding treatments of LDX2404 lean duplex stainless steels for dry wear and corrosion-wear applications, respectively.

Author Contributions: H.D. and X.L. conceived the research concept, provided all research facilities, supervised the research project and finalised the paper. W.D. performed the experimental work, collected data and drafted the manuscript. L.T. contributed to some of the experimental work and helped to interpret the results and improved the manuscript.

Funding: The authors are also grateful to the grant provided by the Newton Mobility Grant from Royal Society, UK (IE151027).

Conflicts of Interest: The authors declare no conflict of interest. 


\section{References}

1. Elhoud, A.M.; Renton, N.C.; Deans, W.F. Hydrogen embrittlement of super duplex stainless steel in acid solution. Int. J. Hydrogen Energy 2010, 35, 6455-6464. [CrossRef]

2. Li, X.Y.; Dong, H. Effect of annealing on corrosion behaviour of nitrogen $\mathrm{S}$ phase in austenitic stainless steel. Mater. Sci. Technol. 2003, 19, 1427-1434. [CrossRef]

3. Fossati, A.; Borgioli, F.; Galvanetto, E.; Bacci, T. Corrosion resistance properties of glow-discharge nitrided AISI 316L austenitic stainless steel in $\mathrm{NaCl}$ solutions. Corros. Sci. 2006, 48, 1513-1527. [CrossRef]

4. Dong, H. S-phase surface engineering of Fe-Cr, Co-Cr and Ni-Cr alloys. Int. Mater. Rev. 2010, 55, 65-98. [CrossRef]

5. Li, X.Y.; Habibi, N.; Bell, T.; Dong, H. Microstructural characterisation of a plasma carburised low-carbon Co-Cr alloy. Surf. Eng. 2007, 23, 45-51. [CrossRef]

6. Li, X.Y.; Buhagiar, J.; Dong, H. Characterisation of dual S phase layer on plasma carbonitrided biomedical austenitic stainless steels. Surf. Eng. 2010, 26, 67-73. [CrossRef]

7. Li, W.; Li, X.; Dong, H. Effect of tensile stress on the formation of S-phase during low temperature plasma carburising of 316L foil. Acta Mater. 2011, 59, 5765-5774. [CrossRef]

8. Liu, R.; Li, X.; Dong, H. Surface modification of medical grade Co-Cr alloys by low-temperature plasma surface alloying with nitrogen and carbon. Surf. Coat. Technol. 2013, 232, 906-911. [CrossRef]

9. Tschiptschin, A.P.; Varela, L.; Pinedo, C.E.; Li, X.Y.; Dong, H. Development and microstructure characterization of single and duplex nitriding of UNS S31803 duplex stainless steel. Surf. Coat. Technol. 2017, 327, 83-92. [CrossRef]

10. Chen, J.; Li, X.Y.; Bell, T.; Dong, H. Improving the wear properties of Stellite 21 alloy by plasma surface alloying with carbon and nitrogen. Wear 2006, 264, 157-165. [CrossRef]

11. Bielawski, J.; Baranowska, J. Formation of nitrided layers on duplex steel—Influence of multiphase substrate. Surf. Eng. 2010, 26, 299-304. [CrossRef]

12. Li, X.Y.; Roberts, R.; Dou, W.B.; Dong, H.S. Low temperature plasma surface alloying and characterisation of a superduplex stainless steel. Int. Heat Treat. Surf. Eng. 2014, 8, 61-64. [CrossRef]

13. Chiu, L.H.; Su, Y.Y.; Chen, F.S.; Chang, H. Microstructure and Properties of Active Screen Plasma Nitrided Duplex Stainless Steel. Mater. Manuf. Process. 2010, 25, 316-323. [CrossRef]

14. Outokumpu-Duplex-Stainless-Steel-Data-Sheet. Available online: https://www.californiaboiler.com/ product-brochures/Outokumpu-Duplex-Stainless-Steel-Data-Sheet.pdf (accessed on 19 July 2018).

15. Wriedt, H.A.; Gokcen, N.A.; Nafziger, R.H. Bulletin of Alloy Phase Diagrams; Springer US: New York, NY, USA, 1987; Volume 8.

16. Tayyaba, Q.; Farooq, H.; Shahid, M.; Jadoon, A.K.; Shahzad, M.; Qureshi, A.H. On the stress corrosion cracking of lean duplex steel in chloride environment. IOP Conf. Ser. Mater. Sci. Eng. 2014, 60, 012066. [CrossRef]

17. Larisch, B.; Brusky, U.; Spies, H.J. Plasma nitriding of stainless steels at low temperatures. Surf. Coat. Technol. 1999, 116-119, 205-211. [CrossRef]

18. Blawert, C.; Mordike, B.L.; Jirásková, Y.; Schneeweiss, O. Structure and composition of expanded austenite produced by nitrogen plasma immersion ion implantation of stainless steels X6CrNiTi1810 and X2CrNiMoN2253. Surf. Coat. Technol. 1999, 116-119, 189-198. [CrossRef]

19. Bachus, L.; Custodio, A. Chapter 16-Avoiding wear in centrifugal pumps. In Know and Understand Centrifugal Pumps; Elsevier Inc.: Amsterdam, The Netherlands, 2003; pp. 232-237.

20. Marinescu, I.D.; Rowe, W.B.; Dimitrov, B.; Inasaki, I. Tribochemistry of Abrasive Machining-15. In Tribology of Abrasive Machining Processes; Elsevier Inc.: Amsterdam, The Netherlands, 2004; pp. 587-633.

(C) 2018 by the authors. Licensee MDPI, Basel, Switzerland. This article is an open access article distributed under the terms and conditions of the Creative Commons Attribution (CC BY) license (http://creativecommons.org/licenses/by/4.0/). 